\title{
Describing and facilitating productive teaching talk in a faculty online learning community
}

\author{
Alexandra C. Lau, ${ }^{1}$ Melissa H. Dancy, ${ }^{1}$ Charles Henderson, ${ }^{2}$ and Andy Rundquist ${ }^{3}$ \\ ${ }^{1}$ Department of Physics, University of Colorado, 390 UCB, Boulder, CO 80309 \\ ${ }^{2}$ Department of Physics and Mallinson Institute for Science Education, \\ Western Michigan University, 1903 W. Michigan Ave., Kalamazoo, MI 49008 \\ ${ }^{3}$ Department of Physics, Hamline University, MS-C1913, 1536 Hewitt Ave., St. Paul, MN 55104
}

\begin{abstract}
This paper presents our preliminary work towards being able to describe productive conversations in the context of faculty talking about teaching in a Faculty Online Learning Community (FOLC) as well as facilitator moves that lead to productive conversations. We present an analysis of a short video clip from a particularly productive FOLC meeting in which a rich discussion of pedagogical issues occurs. In order to understand why this conversation was productive, we describe the types of talk present and the function each type of talk served. Drawing from the literature on teacher workgroup conversations and using an emergent coding scheme, we identify four types of teaching talk: Reflection, Replay, Philosophy, and Rehearsal as well as three facilitation moves: Agency, Withholding, and Elaboration present in the conversation. We consider how teaching talk and facilitation moves are connected and offer guidance for those engaging in facilitation of either online or in-person faculty learning communities.
\end{abstract}

\section{INTRODUCTION}

We offer participants of the Physics and Astronomy New Faculty Workshop the opportunity to extend their learning after the workshop by participating in a yearlong Faculty Online Learning Community (FOLC). The goal of the FOLC is to create reflective and pedagogically knowledgeable practitioners through the support of an ongoing community. Each cohort consists of six to twelve participants who meet biweekly through a video conference call and communicate between meetings through an online bulletin board system. Each cohort is facilitated by one or two more experienced physics faculty members. Further details are available elsewhere $[1,2]$.

Online meetings provide FOLC members with an opportunity to reflect on their teaching and troubleshoot implementation issues they are facing. To see if our FOLCs are functioning as intended, we examine how members talk about their teaching during these biweekly meetings. In this paper we present our preliminary work towards being able to describe 1) productive teaching talk, and 2) facilitator moves that encourage such talk.

\section{TEACHERS' WORKGROUP CONVERSATIONS}

A teacher workgroup is a collection of teachers who collaborate towards a common goal [3]. Our FOLCs are one example of such a group, with the goal of improving reflection and teaching practice. Teacher workgroups provide their members with opportunities to learn (OTLs), but the character of these OTLs are group-dependent [3-5]. Horn and Kane operationalize OTLs by examining the conceptual resources used in a conversation and how the conversation mobilizes teachers for future work [3]. Previous work has analyzed the talk in teacher workgroups in order to specify the nature of OTLs in these groups $[3,5,6]$. This body of work has attempted to answer the questions: What makes a conversation generative for learning? and How does talk afford or constrain OTLs?

The analysis presented in this paper was inspired by the work of Horn and colleagues who have examined these questions in the context of secondary school teacher workgroups. In a qualitative case study, they compared the conversational routines of two workgroups and described how the routines led to different OTLs [6]. In a mixed methods study, they compared the OTLs in workgroups with different levels of accomplished practitioners [3]. In another study they used their analysis of dozens of teacher workgroup meetings to develop a taxonomy for classifying a meeting's OTLs [5]. In all of this work, Horn and colleagues were interested in the nature of the teacher talk and the resources the talk provided for learning.

In the present paper we extend this examination of teaching talk to our physics FOLCs. We posit that a productive conversation necessarily provides group members with multiple OTLs. We define a productive conversation as one in which participants collectively engage in exploration of the pedagogical issue(s) underlying a problem of practice. Using a clip of a FOLC meeting which meets these criteria, we first describe the nature of talk in the clip in order to elucidate what collective exploration of a pedagogical issue can look like, as it can take many forms. We then step back and identify the facilitation moves that encouraged this productive conversation. In combination, this two-level analysis increases our understanding of the dialogue that can lead to learning in FOLC meetings and provides practical advice for facilitators.

\section{DATA \& METHODS}

We analyze video data from a meeting of one of the FOLC cohorts. Present at the meeting were six out of the nine cohort members (not including the facilitator), and all six are female. This meeting was facilitated by one of the authors (Rundquist), a very experienced facilitator. We watched numerous clips across our cohorts and facilitators. We lack space here to discuss all these clips, but they showed us the 
range in nature and quality of conversations occurring during FOLC meetings. Using this perspective, we chose the clip analyzed in this paper based on our sense that it was a good example of productive teacher talk. In the clip, participants engage in exploration of a core pedagogical issue. This is in contrast to other meetings we have seen where the cohort immediately tries to problem solve for one of the members and never goes beyond the surface-level of the problem. In this paper, we make no claim about the frequency of the type of teaching talk in the analyzed clip, nor do we claim that this was the only way the cohort talked about their teaching.

Figure 1 provides a summary of the 15 minute clip. For brevity, the figure includes mostly paraphrases of the talk. All participant names are pseudonyms. In the segment a faculty member discusses her concerns about attendance in her classes. Through a series of questions and comments the facilitator encourages her to expand her thinking and for others to add their ideas to the conversation.

Two of the authors (AL and MD) independently watched the segment and noted salient moments of either participant talk or facilitator moves. Through iterative discussion and suggestions from literature $[3,5,6]$ we settled on 4 codes that described the participant talk and 3 codes that described facilitator moves. In developing the codes for participant (teacher) talk, we started by identifying the constructs used by Horn and colleagues $[3,5,6]$ in our video clip, adding emergent codes as necessary. We then narrowed down our code list by keeping the codes that described the majority of the conversation. These codes are described below. Finally, we asked the facilitator to watch the clip and provide his insights and interpretation of his actions. While we do not have space here to include his commentary, his comments aligned with our (AL and MD) interpretations of the clip. His reflections also made clear that many of the moves he made were intentional.

\section{DESCRIBING PRODUCTIVE TEACHING TALK}

In reviewing the clip, we identified four kinds of teaching talk which we hypothesize contributed to the productivity of the conversation. These types of talk demonstrate one way a cohort can collectively explore a pedagogical issue. Three of the four, Reflection, Rehearsal, and Replay, are elements of teaching talk described in the work of Horn and her colleagues $[3,5,6]$. The below definitions align with those used in this previous work, but are specified for the context of our FOLC meetings. We present examples of each type of talk from the video clip and describe why the talk is productive.

Reflection- Talk was coded as reflection when the participant provided a rationale for their thinking or teaching choices. This was often done as they specified the nature of their problem and/or in response to prodding questions. This talk is productive because it allows the speaker to recognize assumptions they are making and to clarify their thinking.

We see reflective teaching talk throughout this segment. For example, in Event 2 Grace accompanies her question with an explanation of why she is conflicted. She doesn't want to force attendance, but she knows that it is important for success in her class. Following prodding by the facilitator in Event 8, Grace further clarifies her goals for an attendance policy in Event 9: she both wants the students to come to class because it will benefit their learning, but also wants to motivate students to want to come. This reflection on her desired outcome is an important step towards developing a policy that will work for her.

Replay - Talk was coded as replay when participants discussed things they have done in the past. In this clip, replays came in the form of sharing attendance policies people have tried. FOLC members used teaching replays to help them articulate the reasoning behind their choices and/or to support their teaching philosophy. This is productive because instead of relying solely on their sense of how things were generally going in their class, participants used specific classroom moments to support their thinking. For example, in Event 7 Nicole thinks aloud about the specific factors that have impacted attendance in her classes and says that students can become invisible because the sections of her class blend together. After replaying her experience she realizes she needs a better attendance policy. Her previous issues with attendance provide the rationale for developing a new policy.

Rehearsal- Talk was coded as rehearsal when participants considered options for future action. This talk is productive because it is a way to test out ideas before they are implemented. In Event 17, Grace rehearses a possible attendance policy that takes into account her reasoning and goals which she has reflected on throughout the conversation (e.g. in Events 2, 5, \& 9). She explains that her policy will be class dependent (she teaches some very small classes) and it will balance her belief that coming to lecture is important with her desire to treat students as adults.

Philosophy-Talk was coded as philosophy when participants expressed beliefs about teaching and/or learning. Participants talking about their teaching philosophies' is productive because it makes explicit the beliefs that underlie many of the teaching choices they make. For example, in Event 13 Lin says that she does not believe in forcing students to come to class, and this is reflected in her practice of not taking attendance (although she does try to motivate them to come with bonus points). Horn [3, 5, 6] did not have a category that really fit this concept. However, philosophy was so prevalent throughout this clip that we felt it needed to be documented.

We assert that this whole conversation was productive, and applying constructs from the literature plus an emergent factor helps us describe this sense. We do not claim that these are the only types of productive talk nor that all four must be present to make a conversation productive; rather they help us explain why this particular conversation was rich. In reflecting, expressing their teaching philosophy, and using replay and rehearsal, participants went further than trying to just problem solve for Grace. Instead, they shared their thoughts and their thinking processes, making it easier to see in what context their ideas would apply. This clip demonstrates one 


\begin{tabular}{|c|c|c|c|c|c|c|c|}
\hline \multirow[t]{2}{*}{ Summary } & \multicolumn{3}{|c|}{$\begin{array}{c}\text { Facilitation } \\
\text { Moves }\end{array}$} & \multicolumn{4}{|c|}{$\begin{array}{l}\text { Teaching } \\
\text { Talk }\end{array}$} \\
\hline & 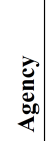 & 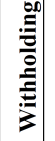 & 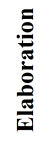 & 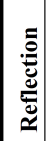 & $\begin{array}{l}\frac{\pi}{0} \\
\frac{a}{2}\end{array}$ & $\begin{array}{l}\frac{2}{a} \\
\frac{0}{0} \\
\frac{0}{2} \\
\frac{0}{2}\end{array}$ & 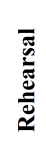 \\
\hline $\begin{array}{l}\text { 1. Facilitator asks Grace to "say a few more thoughts" about the question she previously posted to } \\
\text { the online bulletin board. }\end{array}$ & $\mathrm{x}$ & & & & & & \\
\hline $\begin{array}{l}\text { 2. Grace says, "I'm trying to figure out how important it is to monitor attendance." She explains that } \\
\text { she wants to treat students as grownups but feels they will not be as successful if they don't attend. }\end{array}$ & & & & $\mathrm{x}$ & & $\mathrm{x}$ & \\
\hline 3. Facilitator \& Andrea - Share humorous anecdote. & & & & & & & \\
\hline $\begin{array}{l}\text { 4. Facilitator asks cohort if their attendance concerns depend on if it is an intro vs. advanced course } \\
\text { or small vs. large class. }\end{array}$ & $\mathrm{x}$ & $\mathrm{x}$ & $\mathrm{x}$ & & & & \\
\hline $\begin{array}{l}\text { 5. Grace says in large classes students think it isn't noticeable if they don't show but she notices. } \\
\text { She doesn't think students see the connection between coming to class and success. She worries } \\
\text { people not coming holds their group back. }\end{array}$ & & & & $\mathrm{x}$ & & $\mathrm{x}$ & \\
\hline 6. Facilitator asks cohort if anybody has a different attendance policy based on class. & $\mathrm{x}$ & $\mathrm{x}$ & $\mathrm{x}$ & & & & \\
\hline $\begin{array}{l}\text { 7. Nicole says there is an implicit distinction between lab and lecture (everyone must show up for } \\
\text { lab to get the grade). She talks about when attendance is low or high (i.e. high on quiz days, low on } \\
\text { Fridays). States she needs to come up with an attendance policy for future semesters and posits } \\
\text { using reading quizzes as a solution. }\end{array}$ & & & & $\mathrm{x}$ & $\mathrm{x}$ & & $\mathbf{x}$ \\
\hline $\begin{array}{l}\text { 8. Facilitator says if students aren't convinced of value of class time they view an attendance policy } \\
\text { as "high school again." Asks Grace if she is more interested in motivating students to want to attend } \\
\text { or wanting to get them to attend because she knows it is best for them. }\end{array}$ & $\mathrm{x}$ & $\mathrm{x}$ & $\mathrm{x}$ & & & $\mathrm{x}$ & \\
\hline $\begin{array}{l}\text { 9. Grace responds, "It's a little bit of both." She says it is important for them to pass, but it is hard to } \\
\text { motivate them when it is not their major. }\end{array}$ & & & & $\mathrm{x}$ & & $\mathrm{x}$ & \\
\hline 10. Facilitator asks for other input; Asks if anyone has an attendance policy they like. & $\mathrm{x}$ & $\mathrm{x}$ & $\mathrm{x}$ & & & & \\
\hline $\begin{array}{l}\text { 11. Kristin says her attendance policy is encapsulated in participation grade. This semester she } \\
\text { implemented JiTT. She feels JiTT questions motivated students to show up as they had already } \\
\text { invested time in preparing for class. }\end{array}$ & & & & $\mathrm{x}$ & $\mathrm{x}$ & & \\
\hline 12. Facilitator asks for other ideas/policies. & $\mathrm{x}$ & $\mathrm{x}$ & & & & & \\
\hline $\begin{array}{l}\text { 13. Lin explains that she doesn't take attendance. She doesn't want to force students to come, but } \\
\text { she offers bonus points in class to encourage students to attend. She elaborates on situations she has } \\
\text { encountered at her institution. }\end{array}$ & & & & $\mathrm{x}$ & $\mathrm{x}$ & $\mathrm{x}$ & \\
\hline $\begin{array}{l}\text { 14. Facilitator says he wants to build a setting where students are upset if they miss class because } \\
\text { that is where they view learning as happening. Asks if others agree. }\end{array}$ & $\mathrm{x}$ & & $\mathrm{x}$ & & & $\mathrm{x}$ & \\
\hline $\begin{array}{l}\text { 15. Mila agrees. She gives one point for a clicker question in class and that motivates them to } \\
\text { attend. She tries to emphasize why she wants them to discuss things in class. She states there is } 10 \% \\
\text { of the class you can't do anything about. }\end{array}$ & & & & $\mathrm{x}$ & $\mathrm{x}$ & $\mathrm{x}$ & \\
\hline $\begin{array}{l}\text { 16. Facilitator says his preference is not to set a policy. Talks about experience with oral exams. } \\
\text { Asks Grace, "where do you think you're going to land?" }\end{array}$ & $\mathrm{x}$ & & & & $\mathrm{x}$ & $\mathrm{x}$ & \\
\hline $\begin{array}{l}\text { 17. Grace responds, "It's going to be class dependent." She maybe will allow some absences until a } \\
\text { certain level and can't miss lab. Elaborates on her concern for a small class she will be teaching. } \\
\text { Says her policy will leave room for students to be adults, but at the same time emphasize that } \\
\text { coming to lecture is important. }\end{array}$ & & & & $\mathrm{x}$ & & $\mathrm{x}$ & $\mathrm{X}$ \\
\hline
\end{tabular}

FIG. 1. Description of the 15 minute clip. All talk is paraphrased except where quotation marks are used.

type of rich discussion that can occur in a FOLC: Participants can engage in talk which allows them to reflect on their teaching challenges and leave with solutions that work for them.

\section{PRODUCTIVE FACILITATION MOVES}

Below we detail facilitator moves that we hypothesize encouraged productive teaching talk. It is beyond the scope of this paper to prove a definitive relationship between facilitation moves and productive talk. We offer these moves and discuss their relationship to the talk in this clip as preliminary evidence of potentially productive facilitation techniques.

Agency-The code agency was used to describe facilitator moves that focused on the concerns, interests, and ideas of the participants. This includes moves by the facilitator to encourage others to join the conversation.
Relationship to teaching talk: Participants maintained high agency in this segment which was enabled by facilitator moves. The facilitator's talk is coded with giving agency all but once in the conversation. He repeatedly asks for participants' experiences and ideas (e.g. Events 6, 10, 12, 14), and by the end of the conversation every member has spoken. In eliciting their policies and their opinions, he gives the participants chances to act as experts with valuable teaching knowledge to share. Critically, he repeatedly returns the conversation to Grace (e.g. Events 1, 8, 16) allowing her to articulate her concerns and to clarify her goals. At the close of the clip, the facilitator gives Grace the chance to synthesize all she has heard and rehearse a solution that is uniquely hers.

Withholding-Withholding is used to note when the facilitator is not disclosing his own opinion. This can also take the form of not attempting to immediately solve the problem poser's issue. In this clip, withholding was always coded with 
agency because the facilitator paired holding back his opinion with asking cohort members for theirs.

Relationship to teaching talk: We argue that the facilitator's withholding encouraged productive teaching talk. At first, the facilitator strongly withheld his opinion on attendance policies (Events $4 \& 6$ ). As the conversation continued, he gave a hint of his own opinion (Event 8), but then continued to withhold (Events $10 \& 12$ ) until he eventually fully weighed in on the issue (Events $14 \& 16$ ). Withholding turned the conversation back to the participants; by the time the facilitator fully shared his stance, all but one participant had expressed their ideas. By withholding, the facilitator gave the cohort members space to replay and reflect on their experiences. Withholding also meant that participants maintained the agency to choose what would work in their classrooms, as they saw there was no single, "correct" solution.

Elaboration-Elaboration is a facilitation move to encourage participants to specify and more deeply explore the problem, context, and/or idea they are talking about. This includes asking guiding questions meant to direct participants' considerations towards core issues.

Relationship to teaching talk: In this segment, the facilitator uses elaboration moves to scaffold the conversation. He asks questions that direct participants to consider both the practicalities of the problem they are facing and underlying pedagogical issues. For example, in Event 8 he asks Grace to specify her motivation for creating an attendance policy. She then reflects on her goals and articulates part of her teaching philosophy. In Events 4 and 6 the facilitator prompts the group to consider if attendance policies should be classdependent, guiding members to think about when and why they have attendance policies. Grace and Nicole voice their reflections on this more general question. Using elaboration moves, the facilitator solicits reflection, replay, explanations of teaching philosophy, and rehearsal from the cohort.

Frequently the facilitator is coded at multiple facilitation moves. At least in this meeting, giving agency, withholding an opinion, and asking for elaboration are complementary moves. While we cannot claim that these moves caused the productive talk seen in this clip, we do argue that the moves created opportunities for such talk to occur. These facilitation moves are not unique to an online environment. The general principles of giving participants ownership over their challenges, and guiding them to think about their motivations and context, can encourage productive talk in a variety of settings.

\section{CONCLUSIONS AND NEXT STEPS}

In this paper we analyzed the talk during a particularly productive FOLC conversation. We applied constructs from the literature to the meeting clip in order to describe what the collective exploration of a pedagogical issue looked like in this meeting. These constructs gave us a language with which to explain what made this particular conversation productive. We have argued that these types of talk (reflection, replay, rehearsal, and philosophy) are desirable given our claim that productive conversations provide participants with OTLs. The FOLC meetings are one of the main ways the cohort interacts and our analysis of the teaching talk is valuable because it helps us conceptualize what can occur during these meetings.

In the second part of this paper we described facilitation moves that seemed to encourage productive talk. These moves (giving agency, withholding, and asking for elaboration) kept the conversation participant-centered and created space for productive teaching talk. Other learning communities hoping to provide similar opportunities may consider applying the facilitation moves discussed here. These moves could also be used to guide discussion and decision making during in-person faculty meetings.

This is the first step in an ongoing research agenda. We assert this example shows the FOLC can provide a valuable space for productive talk. However, based on our preliminary review of multiple other cohort meetings, we know the types of talk which contributed to the productivity of this meeting do not always occur and there are likely other types of productive talk. We plan to review more video meetings to see the different ways our cohorts engage in teaching talk and the nature of the conversations these different types of talk afford. From a practical standpoint this work will inform the training we give our facilitators. As we examine more videos we plan to describe the additional facilitation moves we see occurring and the types of talk they lead to.

\section{ACKNOWLEDGMENTS}

We sincerely thank all of our FOLC facilitators. This project is funded by NSF grants DUE-0813481, DUE0121384 , and DUE-9554738.
[1] A. Lau, M. Dancy, J. Corbo, C. Henderson, and A. Rundquist, in Physics Education Research Conference 2017 (Cincinnati, OH, 2017), PER Conference, pp. 232-235.

[2] M. Dancy, A. Lau, J. Corbo, C. Henderson, and A. Rundquist, in Physics Education Research Conference 2017 (Cincinnati, OH, 2017), PER Conference, pp. 100-103.

[3] I. S. Horn and B. D. Kane, Journal of the Learning Sciences 24, 373 (2015).
[4] J. Greeno and M. Gresalfi, Opportunities to learn in practice and identity (Cambridge University Press, Cambridge, 2008), pp. 170-199.

[5] I. S. Horn, B. Garner, B. D. Kane, and J. Brasel, Journal of Teacher Education 68, 41 (2017).

[6] I. S. Horn and J. W. Little, American educational research journal 47, 181 (2010). 